\title{
Bespoke Adaptation in Rural Africa? An Asset-Based Approach from Southern Ethiopia
}

\author{
Rahwa Kidane ${ }^{1}$, Martin Prowse ${ }^{2}$ and Andreas de Neergaard ${ }^{3}$
}

\begin{abstract}
Debates on adaptation in rural Africa rarely consider how responses to climate variability vary by wealth group. This study examines differences in farmers' perceptions of climate variability, current adaptation responses and barriers to adaptation in Southern Ethiopia across wealth groups created through principal components analysis, cluster analysis triangulated with participatory methods. Results indicate that perceptions of weather variability and extreme events are detected by most households regardless of wealth status. The most common responses - using drought-resistant crops and changing planting dates - are also similar across groups. However, there are significant differences in the type of adaptation options by wealthier and poorer farmers: the former intensify agriculture through improved seed varieties, fertilizer and manure; the latter depend on craft activities, seasonal migration and support from relatives and neighbours. Overall, our findings suggest that measuring asset holdings could allow a differentiated approach to supporting adaptation across socioeconomic groups in rural regions in Ethiopia and Africa more broadly.
\end{abstract}

Keywords: Smallholders, adaptation, wealth groups, Ethiopia, Africa

\footnotetext{
${ }^{1} \mathrm{PhD}$ Candidate, Geography, Environment and Population, School of Social Sciences, University of Adelaide, South Australia, SA 5005.

${ }^{2}$ Department of Human Geography, Lund University, Sölvegatan 10, SE-223 62 Lund, Sweden (corresponding author). E-mail: prowsemartin@hotmail.com

${ }^{3}$ Faculty of Social Sciences, University of Copenhagen, Copenhagen K, Denmark.
} 


\section{INTRODUCTION}

Projections from the Intergovernmental Panel on Climate Change (IPCC) for sub-Saharan Africa suggest temperatures will increase more than the global average and precipitation is expected to decrease in parts of the continent. In Ethiopia, average minimum and maximum temperatures have increased by $0.4{ }^{\circ} \mathrm{C}$ and $0.2{ }^{\circ} \mathrm{C}$ respectively from 1951-2002 (Conway et al 2004; see also Deressa et al 2009). Moreover, a significant reduction of precipitation has been observed in eastern, southern and south-eastern parts of Ethiopia since 1982 (Seleshi and Zanke, 2004). National projections of rainfall intensity are mixed with both increasing and decreasing scenarios depending on the model used (Strzepek and Mccluskey 2006).

Such changes in climate pose threats to water security and agricultural production (IPCC 2014; Sivakumar et al 2005). The IPCC predicts with a high level of confidence that climate change will exacerbate existing water shortages across Africa (Niang et al 2014). Moreover, several studies forecast an overall negative effect of climate change on crop yields in many parts of the continent (Berg et al 2013; Müller et al 2011). Climate change is also likely to harm livestock production through limited water and forage availability and changes in the distribution and transmission of diseases (Thornton et al 2007).

Ethiopian agriculture contributes $40 \%$ of GDP, $90 \%$ of exports and employs $90 \%$ of the poor (Diao 2010). Changes in the timing and amount of rainfall are projected to reduce agricultural production across key regions of the country (Ferede et al 2013, Robinson et al 2013). Such reductions are likely to reinforce the very high levels of consumption and multi-dimensional poverty in rural Ethiopia which have varied between 48-57\% from 1994 to 2009 (Brück and Kebede 2013). Over 50\% of households from the Ethiopian Rural Household Survey waves in 2004 and 2009 reported experiencing a drought since 1994, forcing many households below the consumption poverty line (ibid). Current El Niño conditions have led to more than 10.2 million people requiring emergency food assistance (HDR 2016; see also Conway and Schipper 2011) which is leading to an increase in poverty, morbidity and mortality.

Climate adaptation seeks to moderate harm from changes in the climate or to exploit beneficial opportunities (Adger et al 2003; Bryan et al 2013). Adaptation can be planned (Smith et al 2000), autonomous or a mixture of the two (Fisher et al 2010). Individual and community perception of 
climate change and its risks are important elements of this process (Adger et al 2007; Bryan et al 2009; Maddsion 2007). Indeed, local people's understanding and interpretation of change is a critical component in the design of effective policies and response strategies (Hartter et al 2012).

But it is also the case that whilst the perception of a risk is necessary condition for successful adaptation, it is not sufficient. Barriers hinder adaptation by delaying the adaptation process or by making it inefficient or ineffective (Moser and Ekstrom 2010). Such adaptation constraints are defined as "factors that make it harder to plan and implement adaptation options" (Klein 2014, p. 907). Such barriers can arise from cultural (Adger et al. 2009; Nielsen and Reenberg 2010) or cognitive factors (Grothmann and Patt 2005). They can also simply arise from existing socioeconomic conditions (Gbetibouo 2009).

This article uses an asset-based approach to adaptation to investigate how the perception of risk, and adaptation choices and constraints vary among smallholder farmers with different socio-economic conditions (see Stein and Moser, 2014). We utilise an asset-based approach to understanding adaptation decisions because assets not only provide a multi-dimensional set of indicators but also a more stable measure of adaptive capacity and long-term trajectories of well-being (see Carter and Barrett, 2006). In this respect, asset holdings are an excellent proxy for adaptive capacity as they are an imperfect but pertinent predictor of future household conditions. Asset-based approaches can highlight households who adopt defensive risk-management strategies and thus are not able to adapt by entering higher-return activities (on this point see Zimmerman and Carter 2003). Of particular interest in this regard is the degree to which households are able to successfully diversify activities within agriculture and outside agriculture (see Ellis, 2000; Haggblade et al 2010; Dorwood et al, 2009; Alobo, 2015).

Within the adaptation literature, one suggestion is that diversifying into non-farm activities (using a sectoral distinction) is preferable to activities tied to farming (see Sabates-Wheeler et al, 2008). For example, Thomas and Twyman (2003, p.118) took this argument to an extreme when they stated that "diversification within natural-resource use may be regarded as reinforcing vulnerability to climate change". Some rural non-farm income flows have different risk profiles to rain-fed farming (for example, employment in manufacturing, or the receipt of remittances from migration). Such flows help to decouple the household from the harmful effects of seasonality and risks inherent within farming. For example, Bryan et al (2009) found that after age and education, the receipt of non-farm income contributed most to positive adaptation options in agricultural livelihoods. 
There is a growing body of empirical work across different parts of Africa that analyses identifies household-level adaptation measures and constraints to adaptation (e.g. Maddison 2007; Tambo and Abdoulaye 2013; Tessema et al 2013) as well as the determinants of adaptation strategies (e.g. Below et al 2012; Hisali et al 2011; Wood et al 2014). A number of studies have also explored and compared farmers' perceptions with meteorological data (e.g. Meze-Hausken, 2004; West et al 2008). However, there is a limited literature on specific adaptation strategies employed by different wealth groups and also how perceptions and constraints might differ between groups (for example, Deressa et al 2009, Bryan et al 2009, Ziervogel et al 2006).

We aim to contribute to these studies by explicitly focusing on household wealth and how perceptions, adaptation and constraints vary within a community. More specifically, we focus on the extent to which wealth groups are diversifying on the farm or through non-farm activities (using a sectoral distinction). The analysis provides practitioners with important information on how to better facilitate strategies that address the specific needs and barriers among different socio-economic groups, not least as climate adaptation has yet to be integrated in the Ethiopian research and extension system (Bewket 2012; Kassie et al 2013). As explained in the following section, our wealth groups of rich, medium and poor are relative terms: they refer to relative asset holding levels within this kebele and district. The absolute asset holdings of a 'rich' or 'poor' household in different districts, zones and states in Ethiopia (and more broadly in Africa) would differ significantly.

The article consists of four further sections. Section 2 describes the study area, data collection methods and analytical techniques employed in this study. Section 3 presents the findings on farmers' perceptions of climate change and its impacts, adaptation strategies and constraints. Section 4 discusses the implications of the findings for asset-based approaches to adaptation and livelihood diversification. Conclusions and policy suggestions are discussed in Section 5.

\section{RESEARCH PERFORMED}

Fieldwork was conducted between December 2013 and April 2014 in Chencha district, located in the Gamo Gofa administrative zone of the Southern Nations, Nationalities and Peoples' Regional State (SNNPR) of Ethiopia. As of 2007, the district had an area of $373.6 \mathrm{~km}^{2}$ and a population size of 
125,628 in 21,655 households. The study employed a multistage sampling technique for the survey. From the 45 kebeles (the smallest administrative unit of Ethiopia) in the district, one kebele (Gema) was selected purposively. Gema has a total population size of 1,709 and is located $12 \mathrm{~km}$ away from Chencha town. The rationale for selecting this kebele was that it received little attention from governmental and non-governmental institutions - it has poor roads, no electricity and no mobile network - despite variable climatic conditions. The area is mainly characterized by woinadega (a common name given to the agro-ecological zone between 1900 and 2300 metres) with a mixed croplivestock farming system. The total number of household heads in the kebele was 262.

From the 262 household heads in Gema, 121 households were randomly selected. Initially, focus group discussions and key informant interviews were employed. Transect walks and participant observation were also important data collection tools during the study period. Data collection was mainly undertaken at farmers' homes or on their land. All interviews were conducted in either Amharic or the vernacular Gamogna language, sometimes with the help of an interpreter. A participatory wealth ranking exercise took place with 15 key informants who represented all 8 villages (see Table 1). The wealth indicators suggested by respondents were included in the household questionnaire. Key informants categorized every household as either wealthy, middle or poor. The questionnaire was pretested with 10 farmers from the neighbouring kebele and modified accordingly.

For the classification of surveyed household into different wealth groups, principal component analysis (PCA) and cluster analysis techniques (CA) were used. The first step in this analysis was to identify assets based on a common livelihoods framework (Ellis 2000). The following variables were then chosen to represent five key assets:

- Human capital: educational level of the household head; and the active labour force (in adult equivalent figures)

- Social capital: access to formal institutions, such as extension and credit services

- Natural capital: total land holding in hectares; livestock measured in tropical livestock units

- Physical capital: type of house the household owned and possession of goods and equipment such as chairs, tables and farming tools, in Ethiopian birr

- Financial capital: Annual income of the household obtained from farm and non-farm income sources in 2012/13, in Ethiopian birr 
First, to assess the relationship between each variable, a correlation test was carried out which confirmed that all variables were significantly correlated either the $99 \%$ or $95 \%$ level. The KaiserMeyer-Olkin measure of sampling adequacy (0.85) confirmed the suitability of the data for PCA. PCA extracted two components. We retain the first component, which represented $48 \%$ of the underlying variance in the original variables, for further analysis. Instead of creating three wealth groups based on the standardized wealth variable created by PCA, we utilize the first component along with those variables which contributed more than 0.5 in the PCA as input variables in cluster analysis.

A two-way clustering approach was used to aggregate wealth groups (Dossa et al 2011). This approach detects an ideal number of clusters automatically but it also allows the user to fix the required number. In our analysis, the approach suggested a three-cluster solution. This was retained because it corresponded with key informants' classification and because the silhouette measure of cluster cohesion and separation was good (0.6). Furthermore, a cross tabulation of the three cluster solution with local criteria wealth groups indicated a strong relationship (Chi-square $=145, \mathrm{df}=4$ and $\mathrm{P}<0.001)$. Remarkably, only 18 of the 121 households $(14.9 \%)$ did not feature on the same wealth group for subjective participatory and objective PCA/CA methods (see Table 2, which shows a transition matrix between participatory and statistical wealth groups).

The use of PCA and CA is a relatively new approach to the creation of wealth groups (for the former, see Filmer and Pritchett, 2001; for the latter see Dossa et al, 2011). The benefits of our approach are that PCA allows multidimensional wealth/poverty to be captured in a single index and that CA is an objective approach to group formation (especially when using a 2-step solution, as we do). The drawbacks of such an approach are that PCA usually only captures a proportion of asset holdings (often the proportion included in the first component, in our case 48\%) and that CA necessitates the use of a number of continuous variables, not just a single asset index from PCA (following Dossa et al, 2011, we use the most influential asset variables in addition to the single PCA asset index). Table 3 shows the main characteristics of wealth groups.

$<$ Insert Tables 1, 2 and 3 around here) 


\section{RESULTS}

The results are presented in four sections. First, farmers' perceptions of climatic change including a comparison with meteorological data. Second, we describe smallholders' experience of changing agronomic conditions and the impact on their livelihoods. Third, we turn to smallholders' adaptation and coping strategies including non-farm activities. Fourth, we report smallholders' perceived barriers to adaptation. In each section we highlight how our findings correspond to the relevant broader literature.

\section{Farmers' perceptions of climatic change}

During the survey, respondents were asked whether farm households had experienced changes in temperature, rainfall and extreme weather events over the past 10 years. A large majority of farmers $(81.8 \%)$ perceived an increase in temperature and perceived a decrease in precipitation (84.8\%) (with no significant differences across wealth groups). These findings correspond with other studies from different parts of Africa that document farmers' perceptions of a changing climate (see Deressa et al 2011; Tambo and Abdoulaye 2013).

Turning to extreme weather conditions. key informants suggested droughts had occurred in the kebele in 2006-07, 2007-08, 2008-09 and 2009-10. The 2007-08 drought was the most serious with very low rainfall during the main mehere rainy season. Whilst droughts were reported in a uniform fashion by all wealth groups, flood events showed greater variation (see Figure 1).

$<$ Figure 1 around here, see attached file $>$

Perceptions of climate change were also assessed during focus group discussions and semi-structured interviews. Generally, both men and women supported the survey results on temperature and rainfall. However, participants in group discussions focused more on rainfall variability than an increasing or 
decreasing trend. All members agreed the short rainy season (belg) is no longer consistent. In addition, many group participants reported fewer rainy days in the belg season. A similar observation has been made by Speranza et al (2010) with agro-pastoralists in Kenya. Participants also indicated very heavy rains during the main rainy season (mehere) leading to flooding and soil erosion.

Comparison of meteorological data with farmers' perceptions of climate change

Farmers' perceptions of climate change were compared with 10 years of annual rainfall and temperature records provided by Dorza Meteorological Station. The maximum and minimum temperature records suggest an increasing trend during the past decade which matches farmers' perceptions (minimum temperature $\mathrm{y}=0.0339 \mathrm{x}+12.173, \mathrm{R}^{2}=0.2278$; maximum temperature $\mathrm{y}=$ $\left.0.0723 x+20.922, R^{2}=0.3517\right)$. Furthermore, annual rainfall generally exhibited a slight downward trend over the 10 year period with considerable variability.

Many factors have been shown to influence farmers' perceptions of climatic change (Bryan et al 2009; Hansen et al 2004). Discrepancies may occur due to the fact that farmers recall extreme weather events from recent years (Slegers 2008). It could also be the case that farmers strongly associate a delay in rain during planting with a reduced total amount, although data may not show any significant downward trend. Similarly, perceptions may also be influenced by a lack of alternative water sources available for cropping (NMSA 2001). However, in a similar manner to Dang et al (2014), Roco et al (2015) and West et al (2008), in this study we find a similarity between farmers' perceptions and meteorological data.

Perceived impacts of climate change on natural resources, crop production and livestock

Changes in the climate affect soil quality and water availability in Gema. Of the surveyed households, 97\% reported soil erosion from heavy rain. Almost all respondents (98\%) stated they do not get sufficient water for agriculture, livestock and domestic purposes suggesting an inability to harvest 
and store rainwater. Focus group respondents emphasized how springs are drying up as a result of extended dry periods.

Most smallholders from the survey and focus groups stated that climatic factors are the main cause of the reduced yields in agricultural production. Men stated the very late start of the belg rainy season delays normal planting dates, resulting in shorter growing periods and lower yields for crops that require long growing periods like sorghum (see also Rowhani et al, 2011). Similarly, women stated the delayed onset of precipitation in the belg season delayed the harvesting time of mettatee (sweet potato) which now fails to ripen before the kiremet rain begins. This complicates the normal cropping calendar.

Farmers also face broader challenges to crop production: $49 \%$ reported that crop pests and diseases obstruct farming operations; $35 \%$ reported crop damage from wildlife (on this point see the Mertz et al 2010 study in West Africa). Some of the former were perceived as being induced by changing climatic conditions such as the high incidence of solo (sweet potato weevil) during periods of drought and kishekish (aphids) in beans during hot years. Smallholders also associated a greater incidence of stalk borers on maize and sorghum with a shortage of precipitation.

Smallholders perceived climatic changes as a risk to livestock production, partly through a greater incidence of diseases. Almost all surveyed households (98\%) reported alkit (leech), gandi (tryponasomiasis), and abagoreba (blackleg) in their villages. Leeches are most common during the dry season (when livestock drink from springs), whilst tsetse flies are prevalent during warmer months of the year (see Thornton et al's, 2005, study on tryponasomiasis in Ethiopia). Conversely, blackleg is associated with heavy, unexpected rainfall. Most participants in focus group discussions emphasized the lack of nearby veterinary services as a key factor alongside changes in climatic conditions. On a broader note, survey respondents also considered feed shortages for animals to be a result of frequent drought, and pointed to the reduced growth and birth rate of animals, a reduction in milk products, loss of body weight, and greater frequency of livestock deaths (particularly in 2008). This result is in line with the finding of Silvestri et al (2012) who reported households' experience of feed shortages for livestock in agro-pastoral communities of Kenya.

Overall, all interviewees reported that changes in climatic conditions impose serious challenges on their livelihoods. Respondents attributed increased susceptibility to diseases such as giardiasis, cholera, malaria, the common cold and skin infections with climate variability. For example, malaria 
is a new disease in the locality and men associated the spread of malaria with the drought in 2008. We now turn to smallholders' on-farm and non-farm diversification strategies.

\section{Adaptation and coping strategies}

Farmers in the study area use both coping and adaptation strategies to reduce the impact of climate change. In this paper, the term coping strategy is used to refer to short-term response, and adaptation as a continuous and long-term measure. Accordingly, farmers were asked to indicate the strategies they employ temporarily when they experience a crises (coping) and measures they take with the goal of its current and future benefits (adaptation). Overall, fourteen different strategies were identified. Coping strategies conducted by surveyed farmers in this case study include - participation in craftworks; receiving support through social networks; selling of assets and temporary migration. The changes in farming practices (i.e. on-farm strategies) are considered as adaptation measures. All the coping and adaptation responses will be presented and discussed in the following section.

The study highlighted considerable differences in the on-farm strategies employed by different wealth groups. Five strategies were reported regularly. First, farmers use their indigenous farming knowledge to select crops such as enset (Ensete Ventricosum) and godera (Colcasia Esculenta) which can withstand harsher climatic conditions. Enset trees, besides their cultural value, have a very high drought tolerance, water-holding capacity and the crop can be stored easily. Both surveyed households and focus group participants stated how enset was a safety net in past droughts. Now, consuming enset is practiced by all smallholders during the months of food shortages (mainly in April, May and June) after other crops have been consumed. Almost all smallholders (98\%) adjusted planting dates to the onset of rainfall which helps to protect the sensitive growth stage of crops from water stress.

Smallholders also diversify cropping patterns as an adaptation strategy. Over $95 \%$ of households grow at least two types of crops. Looking into the different wealth groups, all middle and rich households use this strategy $(100 \%)$ compared to only $89 \%$ of poor households (significant at the $95 \%$ level). A comparison of the average number of crops grown across groups - rich households 7.4, middle households 6.1 and poor households 3.8 - is statistically significant at the $99.9 \%$ level $(\mathrm{F}=64.5, \mathrm{p}=0.00)$. 
In response to the shortening of growing seasons, especially the short belg season, $31 \%$ of surveyed households reported they have started using fast-growing varieties which can mature within 3-4 months such as improved wheat varieties and gudana improved potato seed varieties (on this point, see the Thomas et al, 2007, study from South Africa). There is a significant difference (at the $99 \%$ level) in adopting this adaptation strategy $\left(\chi^{2}=25.339\right.$, d.f $\left.=2, p=0.00\right)$ with the majority of rich households (67\%) using improved seed compared to middle (27\%) and poor households (13\%). This chimes with the findings of Kuntashula et al (2015) in Zambia. Moreover, a significantly higher proportion of wealthy and medium households (at the 99\% level) also use both inorganic fertilizers and manures compared to only $35 \%$ and $63 \%$ of poor households, respectively. According to smallholders, applying more nitrogen, potassium and phosphorus compensates for the low yields caused by variable weather conditions. These findings are in agreement with the study by Wood et al (2014) who demonstrated that higher wealth was correlated with on-farm changes in West Africa.

Most farmers employ soil conservation techniques in order to prevent soil erosion. The majority of surveyed households (71\%) planted trees on hillsides around their farms fields to protect soils from being washed away by flooding, 70\% dug micro-basins to store runoff water, preventing the loss of top soil when it rains excessively. Moreover, through the Productive Safety Net Programme and on their own initiative, $58 \%$ of smallholders work on terraces. In addition, $21 \%$ of households conserve water through rainwater harvesting during the rainy season for later use. Whilst a greater number of wealthy households adopted these four strategies than middle and poor farmers, the differences are not statistically significant across the groups. This could be because all farmers, except old people and those who have a health condition, are encouraged by district officers to participate in such practices. We now turn to a variety of non-farm activities conducted by the respondents.

\section{Non-farm activities}

The survey highlighted a range of non-farm diversification strategies. Craftworks such as weaving, smelting iron, tanning skins, carpentry and pottery make a considerable contribution to incomes in poor agricultural seasons. Overall, $52 \%$ of households conducted at least one of these activities. But compared to middle households (45\%) and rich households $(11 \%)$, poor households $(83 \%)$ participated to a much greater extent (significant at the $99 \%$ level - see Table 4). This suggests that poor households spread risk through participation in non-farm activities as opposed to within farming. 
Most surveyed households who participated in craftworks complained that despite their traditional skills, they only make a limited profit due to a lack of linkages with city markets.

Poor households also participated more in seeking material support and informal loans from social networks (see Adger 2010). Over $37 \%$ of poor households rely on relatives and neighbours when they face crises. Table 1 based on early participatory research methods suggests that middle and rich households provide such kinds of support. Indeed, similar observations were made in Central Rift and Kobo valleys of Ethiopia (Kassie et al 2013).

The sale of valuable assets such as livestock, clothes and precious jewellery is also a common strategy. In our study, $21 \%$ of households sold livestock (mainly cattle) during drought periods. This strategy was mainly carried out by wealthy households (46\%) as compared to the middle (16\%) and poor households (10\%) (significant at the 99\% level - see Table 4). This contrasts with the findings of Paul et al (2011) who found that disposal of valuable assets (mainly cattle and chickens) is lower among higher income groups than middle and lower-income groups. An analysis of variance on our data shows that livestock ownership (measured in tropical livestock units - TLU) statistically differs across wealth groups (see Table 4). On average, rich households own 6.7 TLU, middle-class 3.7 TLU and poor households 1.7 TLU ( $\mathrm{p}=0.00)$. We can surmise that the greater level of asset disposal by wealthier farmers is mainly due to having larger asset holdings compared to middle and poor households. Poor farmers in the study area own a maximum two oxen where their main purpose is to supply draught power for agricultural farming. During drought times, poor farmers prefer conducting other non-farm activities rather than selling their livestock as they use them for farming when the weather condition improves. This reflects the deep rural development literature on smallholders taking extreme measures (such as reducing food intake, or engaging in destitution activities) instead of disposing of vital assets such as oxen during times of distress (one starting point being Corbett, 1988).

During the focus group discussions and survey, temporary migration to neighbouring districts and urban areas emerged as a key non-farm strategy in the study area. For example, farmers reported that when weather conditions are unfavourable or when crops yields are low, they migrate to nearby districts (Mirab Abaya and Wolayta) for work. It is mainly poor households (28\%), followed by middle-class households (18\%) who undertake migration as a coping mechanism (significant at the 99\% level - see Table 4). This finding is consistent with previous studies conducted in Ethiopia which show the increased prevalence of migration by men due to climatic changes (Gray and Muller 
2012). However, farmers in our study indicated the strategy is the least desirable due to the instability in earnings and since it weakens social bonds among villagers (on this latter point, see Adger et al. 2013). Participants in the FGDs also complained about their exposure to diseases when they move to new areas.

\section{Perceived barriers to adaptation}

The last section of the results highlights smallholders' perceived barriers to adaptation. The majority $(92 \%)$ regarded a lack of finance as the main barrier, which is consistent with other studies in Ethiopia (Deressa et al 2009), South Africa (Gbetibouo 2009) and Nigeria (Tambo and Abdoulaye 2013). For poor and middle households, lack of finance generally means a severe money shortage due to poverty. Whereas, for the rich households, it is lack of significant amount of money to make heavy agricultural investment. In our study, and unsurprisingly, finance was the main barrier for all poor and middle households $(100 \%)$ followed by rich households $(65 \%)$, significant at the $99 \%$ level. In particular, respondents associate a lack of finance with an inability to purchase yield-improving agricultural inputs such as fertilizer and improved seed varieties. In this respect, the study confirms earlier findings that some adaptation measures may not be economically affordable for smallholder farmers (Adger et al 2007). Exactly 80\% of smallholders also felt that water shortages, such as from irrigation or rain-harvesting techniques, were a barrier to adaptation. Nearly all depend on rain-fed agriculture and only $21 \%$ used rain-harvesting techniques. Comparing wealth categories, a shortage of water was mainly reported by poor households (94\%) followed by middle $(78 \%)$ and wealthy farmers $(62 \%)$, again significant at the $99 \%$ level. Although farmers wish to implement small-scale irrigation using water pumps (mainly for vegetable and cash crop production) their ability to do this is limited (we return to this issue in the conclusion).

Moving from water to land, $51 \%$ of surveyed households reported that a shortage of land impeded their capacity to adapt (see also Bryan et al 2009). Unsurprisingly, a shortage of land was cited by more poor farmers (83\%) than middle (45\%) and wealthy households $(8 \%)$, significant at the $99 \%$ level. The result from a one-way ANOVA also provides supportive evidence that poor respondents have significantly $(\mathrm{p}=0.01)$ lower average land size compared to middle and rich households. This offers some evidence that a lack of access to natural resources is contributing to poorer households' diversification into non-farm strategies. 
Poor infrastructure is also an important adaptation barrier for middle households (55\%), followed by wealthy (42\%) and poor households (37\%). Most household heads complained about the high cost of fertilizer and improved seeds in their kebele compared to the price in Chencha market due to the additional transportation cost attributed to poor road access (see also Mwangi 1996; Tambo and Abdoulaye 2012). As key informants noted, the name Gema itself means 'hidden place'. Our findings chime with the study by Armah et al (2015) in Tanzania where location was a significant barrier to adaptation (above and beyond social and cultural factors).

Lastly, whilst the communication of accurate climate information to help farmers cope with unfavorable conditions is well acknowledged in the literature (Hansen et al. 2007), in our study a lack of information was perceived as an adaptation barrier by only $29 \%$ of surveyed households. A greater number of middle households (33\%) regard the lack of information as barrier to adaptation compared to poor (28\%) and wealthy (23\%) groups (although this was not statistically significant). Whilst there is a Disaster Prevention and Preparedness Office (DPPO) in Chencha District, it provides very little information to smallholders because officials lack financial and human resources.

Figure 2 below summarises the main incidence of key adaptation and coping strategies across the three wealth groups.

$<$ Figure 2 around here, see attached file $>$

\section{DISCUSSION}

Our findings show differences to other studies that have examined adaptation practices across wealth groups. They contrast with Bryan et al (2009) who found that the poorest and middle groups of Ethiopian farmers were more likely to adjust farming practices than rich households. This suggests that regional and local context helps to determine diversification strategies in rural Ethiopia. Our findings also contrast with Ziervogel et al's (2006) study in South Africa which showed that poor 
households depend more on crop diversification as they have limited business opportunities, whereas wealthier farmers specialize within agriculture.

Our results also raise three important questions regarding how we conceptualise adaptation and the role of diversification strategies by smallholder farmers in Africa as a form of adaptation. First, the triangulation of participatory research and analysis of survey data through PCA and CA shows how asset-based indices provide a straightforward and robust approach to creating and comparing wealth groups. The use of the main extracted component from PCA as an input in CA is relatively novel and CA itself offers an objective approach to the creation of groups. Assets provide an excellent basis for measuring adaptive capacity but so far this has mainly been conducted in urban settings (Stein and Moser, 2014; Moser, 2011). This study illustrates an application in a remote rural area and shows how the approach is consistent with smallholders' understanding of differentiation within their own community.

Second, the study shows how pre-existing asset holdings influence the nature of diversification conducted by smallholders: rich households with access to land, water and livestock diversify within farming using technology, local knowledge and asset sales when necessary to overcome climatic variation. Such a finding contrasts strongly with Thomas and Twyman's (2003) assertion that naturalresource-based diversification increases vulnerability. It appears to be the case that asset holdings above a certain threshold maintain ties to land-based livelihood strategies, overcoming greater climatic variability. This is not the case for poor households who, third, are conducting different forms of non-farm diversification: craftworks; migration; relying on social networks. Such activities have a different risk profile to farming but each has certain limits. The provision of non-farm goods and services in the form of craftworks is closely linked to steady local demand. But as climatic change will make agricultural performance in the district more capricious farm incomes will fluctuate more, making demand for non-farm products more uncertain and unreliable. There are also limits to the use of social networks: covariant shocks across a community limit the ability of middle and rich households to redistribute food or cash to kin and neighbours. Migration can also have a downside. Whilst it decouples an individual and household from climatic conditions at home, migration also withdraws labour and expertise from the farm enterprise, possibly leading to a cycle of poor land husbandry and declining yields. Seen from this angle, migration may reinforce maladaptation by increasing food insecurity among those household members who cannot migrate and do not receive regular and sufficient remittances (e.g. elderly households). On the other hand, the receipt of 
sufficient remittances could improve adaptation practices on the farm and thereby may enhance the adaptive capacity of farmers. Our data doesn't allow us to examine the extent to which these processes are taking place. We suggest that future studies should evaluate the effectiveness of be adaptation responses at farm level and the risk of maladaptive outcomes that may arise from such responses. This is clearly an area for further research.

\section{CONCLUSION}

As the Ethiopian climate varies, agriculture will provide a less reliable form of livelihood for many smallholders. But within the same locality, smallholders adapt to these changes in very different ways based on their existing endowments and entitlements. Smallholders' perceptions of climatic differences are important, but they are nowhere near sufficient to enable successful adaptation. We have argued that assets provide a robust multi-dimensional indicator to measure adaptive capacity and to categorise households within a community. Such an approach can also be applied at broader scales. Our findings that rich household diversify within farming and poor households into non-farm strategies contrasts with other studies within Ethiopia and elsewhere in Africa that have focussed on diversification as a form of autonomous adaptation. This clearly has implications for policy which could be tailored towards certain sections of communities. We offer examples from our own study as an illustration.

For rich households who have sufficient assets to overcome increased climatic variability and are diversifying within farming, policy could focus on removing constraints to the intensification of agriculture such as through providing better access to improved seed and to water pumps for irrigation. Intensifying agriculture may provide greater local labour market opportunities for households with less land, and could allow a more stable redistribution of wealth through social networks. It could also ensure more stable demand for the non-farm craftworks supplied by poor households who, without other options, often migrate outside the community. Policies to improve road infrastructure and the transmission of prices and information would not only improve demand for non-farm activities but would also allow migrants to be better informed about local and regional labour market opportunities and, importantly, allow easier flows of remittances back to homesteads and families. Indeed, it appears that improving infrastructure is, in this area, one of the most wealth- 
Kidane, R., Prowse, M. \& de Neergaard, A. European Journal of Development Research (2018). https://doi.org/10.1057/s41287-018-0161-4

neutral adaptation investments that can be made. Overall, our findings suggest that asset holdings analysed through combining principal components analysis and cluster analysis provide an excellent proxy for adaptive capacity. Such an approach allows a differentiated approach to supporting adaptation across socio-economic groups in rural regions in Ethiopia and Africa more broadly. 
Kidane, R., Prowse, M. \& de Neergaard, A. European Journal of Development Research (2018). https://doi.org/10.1057/s41287-018-0161-4

Table 1: Indicators of wealth according to local criteria

\begin{tabular}{|c|c|c|c|}
\hline \multirow{2}{*}{$\begin{array}{l}\text { Local indicators of } \\
\text { wealth }\end{array}$} & \multicolumn{3}{|c|}{ Wealth categories } \\
\hline & Rich households & Medium households & Poor households \\
\hline Farm land size & Own $\geq 3$ ha & Own $\leq 2 \mathrm{ha}$ & Own $\leq 1$ ha \\
\hline Livestock ownership & $\begin{array}{l}\text { Own at least } 4 \text { oxen, } 6 \\
\text { cows, } 1 \text { mule, } 4 \text { goats, } \\
8 \text { chickens, } \\
\text { beekeeping }\end{array}$ & $\begin{array}{l}\text { Own } 2 \text { oxen, } 1 \text { cow, } 6 \\
\text { chicken, } 4 \text { goats, } 1 \\
\text { mule, no beekeeping }\end{array}$ & $\begin{array}{l}\text { Own poultry, no } \\
\text { livestock, no } \\
\text { beekeeping }\end{array}$ \\
\hline Housing condition & $\begin{array}{l}\text { Own a house made } \\
\text { with iron sheet roof } \\
\text { mud brick walls, } \\
\text { cement floor }\end{array}$ & $\begin{array}{l}\text { Own a house made with } \\
\text { grass roof, mud brick } \\
\text { walls and earth floor }\end{array}$ & $\begin{array}{l}\text { Owns a house made } \\
\text { with grass }\end{array}$ \\
\hline $\begin{array}{l}\text { Number of } \\
\text { meals/day }\end{array}$ & $\begin{array}{l}\text { Household members } \\
\text { can eat } 3 \text { times/day }\end{array}$ & $\begin{array}{l}\text { Household members can } \\
\text { eat once or twice a day }\end{array}$ & $\begin{array}{l}\text { Household members } \\
\text { can only eat once } \\
\text { and sometimes } \\
\text { twice }\end{array}$ \\
\hline Food availability & $\begin{array}{l}\text { Have enough food for } \\
\text { the whole year and } \\
\text { reserve surplus crop }\end{array}$ & $\begin{array}{l}\text { Have sufficient food for } \\
\text { the whole year but no } \\
\text { surplus crop }\end{array}$ & $\begin{array}{l}\text { Do not have } \\
\text { sufficient food for } \\
\text { the whole year. } \\
\text { Require food aid } \\
\text { from govt./NGOs }\end{array}$ \\
\hline
\end{tabular}

Source: Participatory wealth ranking exercise with key informants 
Kidane, R., Prowse, M. \& de Neergaard, A. European Journal of Development Research (2018). https://doi.org/10.1057/s41287-018-0161-4

Table 2: Distribution of wealth groups according local criteria * PCA/Two-step cluster

\begin{tabular}{lll|c|c|c|c} 
& & & \multicolumn{3}{c}{ PCA/ Two-step cluster } & \multirow{2}{*}{ Total } \\
& & Poor & Medium & Rich & \\
\hline \multirow{2}{*}{ Local criteriann } & Poor & Count & 43 & 5 & 0 & 48 \\
\cline { 2 - 7 } & Medium & Count & 3 & 36 & 2 & 41 \\
\cline { 2 - 7 } & Rich & Count & 0 & 8 & 24 & 32 \\
\hline \multirow{2}{*}{ Total } & Count & 46 & 49 & 26 & 121 \\
\hline
\end{tabular}

Discrepancies between participatory and statistical wealth group methods shows in grey

Source: Analysis of household survey 
Kidane, R., Prowse, M. \& de Neergaard, A. European Journal of Development Research (2018). https://doi.org/10.1057/s41287-018-0161-4

Table 3: Key characteristics of wealth groups

\begin{tabular}{lccc} 
Indicators of wealth & \multicolumn{3}{c}{ Wealth categories } \\
\hline & 14613.73 & $\underline{\text { Medium }}$ & $\underline{\text { Poor }}$ \\
$\begin{array}{l}\text { Mean annual income in } \\
\text { Ethiopian Birr }\end{array}$ & 8217.75 & 3547.86 \\
$\begin{array}{l}\text { Mean agricultural land in } \\
\text { hectare }\end{array}$ & 2.9042 & 1.634 & 0.464 \\
$\begin{array}{l}\text { Mean tropical livestock unit } \\
\begin{array}{l}\text { Mean durable asset } \\
\text { endowment in Ethiopian birr }\end{array}\end{array}$ & 6.7223 & 3.745 & 1.68 \\
\end{tabular}

Source: Household survey 
Kidane, R., Prowse, M. \& de Neergaard, A. European Journal of Development Research (2018). https://doi.org/10.1057/s41287-018-0161-4

Table 4: Non-farm activities

\begin{tabular}{|c|c|c|c|c|}
\hline \multirow{2}{*}{$\begin{array}{l}\text { Off/non-farm } \\
\text { activities }\end{array}$} & \multirow[t]{2}{*}{ Wealth groups } & \multicolumn{2}{|c|}{ Respondents (\%) } & \multirow[t]{2}{*}{$\mathrm{X}^{2}$ Value } \\
\hline & & Yes & No & \\
\hline \multirow[t]{4}{*}{ Craft works } & Poor & 82.6 & 14.4 & \multirow[t]{4}{*}{$35.3 * * *$} \\
\hline & Medium & 44.9 & 55.1 & \\
\hline & Rich & 11.5 & 88.5 & \\
\hline & Total & 52.1 & 49.0 & \\
\hline \multirow[t]{4}{*}{ Social networks } & Poor & 37 & 63 & \multirow[t]{4}{*}{$32.24 * * *$} \\
\hline & Medium & 0 & 0 & \\
\hline & Rich & 0 & 0 & \\
\hline & Total & 14 & 86 & \\
\hline \multirow[t]{4}{*}{ Livestock sell } & Poor & 10.9 & 81.1 & \multirow[t]{4}{*}{$13.53 * * *$} \\
\hline & Medium & 16.3 & 83.7 & \\
\hline & Rich & 46.2 & 53.8 & \\
\hline & Total & 20.7 & 79.3 & \\
\hline \multirow[t]{4}{*}{ Seasonal migration } & Poor & 28.3 & 71.7 & \multirow[t]{4}{*}{$8.92 * *$} \\
\hline & Medium & 18.4 & 81.6 & \\
\hline & Rich & 0 & 100 & \\
\hline & Total & 18.2 & 81.1 & \\
\hline
\end{tabular}

Note: $* * *$ significant at $1 \%$ level, $* *$ significant at $5 \%$ level

Source: Household survey 
Kidane, R., Prowse, M. \& de Neergaard, A. European Journal of Development Research (2018). https://doi.org/10.1057/s41287-018-0161-4

Figure 1

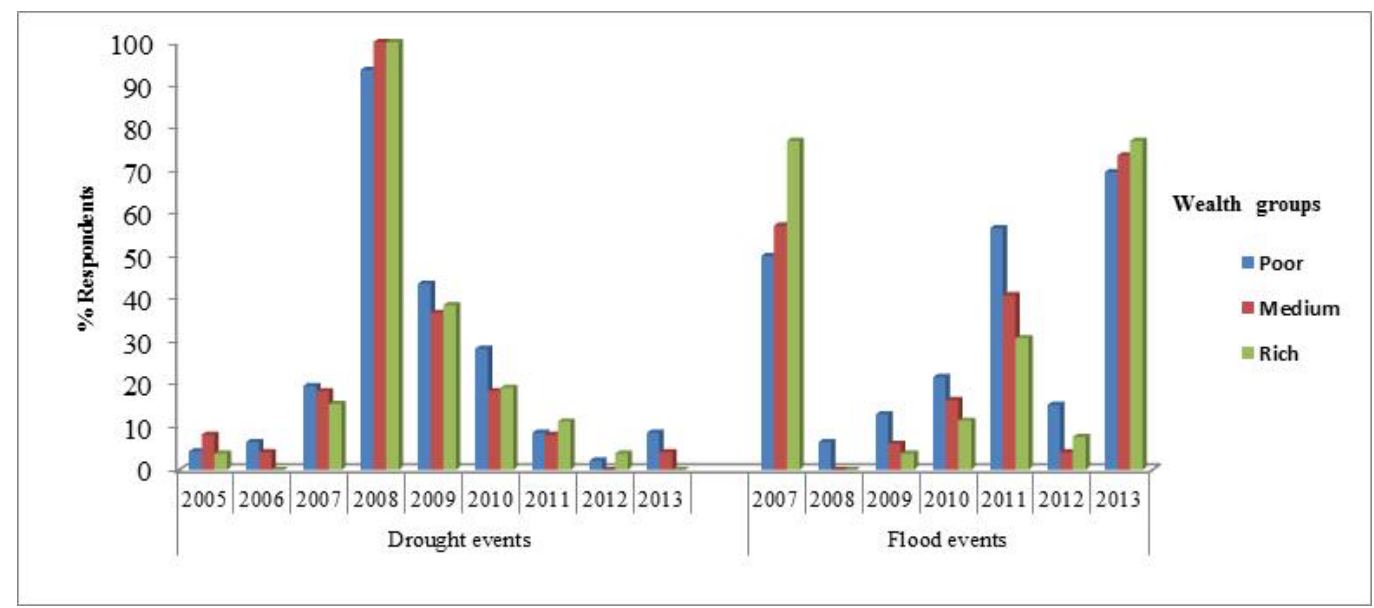

Source: Household survey 


\section{Figure 2}

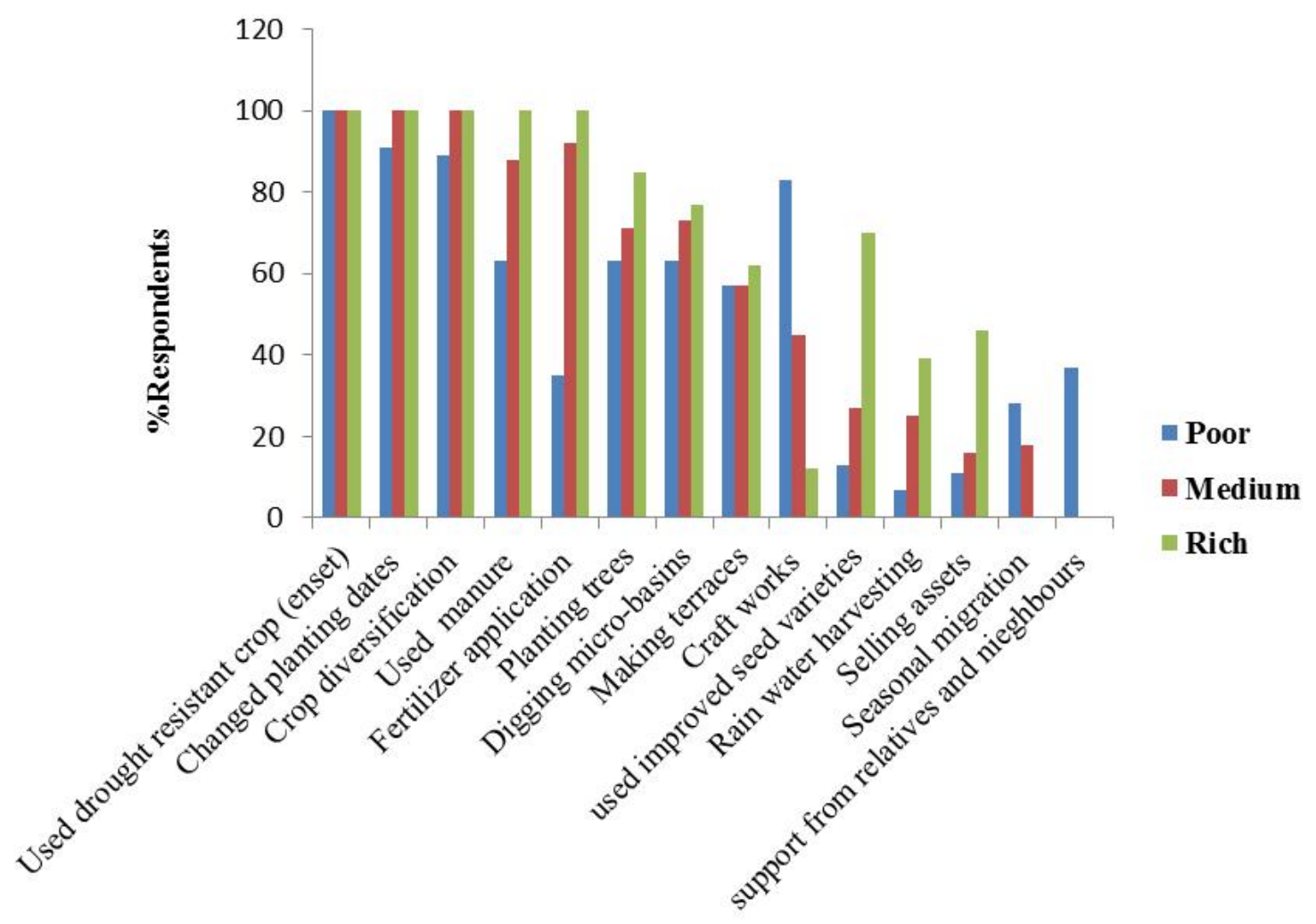

Source: Household survey 


\section{REFERENCES}

Adger WN (2010) Social capital, collective action, and adaptation to climate change. In Der klimawandel (pp. 327-345). VS Verlag für Sozialwissenschaften.

Adger WN, Huq S, Brown K, Conway D, Hulme M (2003) Adaptation to climate change in the developing world. Progress in Development Studies 3:179-195.

Adger WN, Agrawala S, Mirza MMQ et al (2007) Assessment of adaptation practices, options, constraints and capacity. Climate Change 2007:Impacts Adaptation and Vulnerability Contribution of Working Group II to the Fourth Assessment Report of the Intergovernmental Panel on Climate Change Cambridge University Press, Cambridge, UK, 717-743.

Adger WN, Dessai S, Goulden M, Hulme M, Lorenzoni I, Nelson DR, Naess LO, Wreford A (2009) Are there social limits to adaptation to climate change? Climatic Change 93:35-354.

Adger, W. N., Barnett, J., Brown, K., Marshall, N., \& O'Brien K. (2013) Cultural dimensions of climate change impacts and adaptation. Nature Climate Change 112-117.

Alobo, Sarah Loison (2015) Rural Livelihood Diversification in Sub-Saharan Africa: A Literature Review. The Journal of Development Studies 51.9: 1125-1138.

Armah F, Luginaah A, Hambati I, Chuenpagdee H, Campbell R (2015) Assessing barriers to adaptation to climate change in coastal Tanzania: Does where you live matter? Population and Environment 37: 231-263.

Below TB, Mutabazi KD, Kirschke D, Franke C, Sieber S, Siebert R, Tscherning K (2012) Can farmers' adaptation to climate change be explained by socio-economic household-level variables? Global Environmental Change 22: 223-235.

Berg A, de Noblet-Ducoudré N, Sultan B, Lengaigne M, Guimberteau M (2013) Projections of climate change impacts on potential $\mathrm{C} 4$ crop productivity over tropical regions. Agr Forest Meteorol 170: 89-102.

Bewket W (2012) Climate change perceptions and adaptive responses of smallholder farmers in central highlands of Ethiopia. International Journal of Environmental Studies 69:507-523.

Brück T, Kebede SW (2013) Dynamics and Drivers of Consumption and Multidimensional Poverty: Evidence from Rural Ethiopia. IZA Discussion Paper No. 7364, Bonn, Germany.

Bryan E, Deressa TT, Gbetibouo GA, Ringler C (2009) Adaptation to climate change in Ethiopia and South Africa: options and constraints. Environ Sci Policy 12:413-426.

Bryan E, Ringler C, Okoba B, Roncoli C, Silvestri S, Herrero, M (2013) Adapting agriculture to climate change in Kenya: Household strategies and determinants. Journal of Environmental Management 114:26-35. 
Carter, M. R., \& Barrett, C. B. (2006). The economics of poverty traps and persistent poverty: An asset-based approach. The Journal of Development Studies, 42.2|: 178-199.

Conway D, Schipper ELF (2011) Adaptation to climate change in Africa: Challenges and opportunities identified from Ethiopia. Global Environmental Chang 21:227-237.

Conway D, Mould C, Bewket W (2004) Over one century of rainfall and temperature observations in Addis Ababa Ethiopia. International Journal of Climatology 24:77-91.

Corbett, J. (1988) Famine and household coping strategies. World Development, 16 (9): 1099-1112.

Deressa TT, Hassan RM, Ringle C, Alemu T, Yesuf M (2009). Determinants of farmers' choice of adaptation methods to climate change in the Nile Basin of Ethiopia. Global Environmental Change 19:248-255.

Deressa TT, Hassan RM, Ringler C (2011) Perception of and adaptation to climate change by farmers in the Nile basin of Ethiopia. The Journal of Agricultural Science 149: 23-31.

Diao X (2010) Economic importance of agriculture for sustainable development and poverty reduction: The case study of Ethiopia Global forum on agriculture 29-30 November 2010, Policies for agricultural development, poverty reduction and food security $p$ OECD Headquarters, Paris. http://www.oecd.org/agriculture/agricultural-policies/46378942.pdf. Accessed 1 June 2016.

Dorward, Andrew, Anderson, S., Nava, Y., Pattison, J., Paz, R., Rushton, J. and Sanchez Vera, E. (2009) Hanging In, Stepping up and Stepping Out: Livelihood Aspirations and Strategies of the Poor. Development in Practice 19.2: 240-247.

Dossa LH, Abdulkadir A, Amadou H, Sangare S, Schlecht E (2011) Exploring the diversity of urban and peri-urban agricultural systems in Sudano-Sahelian West Africa: an attempt towards a regional typology. Landscape and Urban Planning 102: 197-206.

Ellis F (2000) Rural livelihoods and diversity in developing countries. Oxford, OUP.

Ellis, F. (1998) Household strategies and rural livelihood diversification. The Journal of Development Studies. 35.1: 1-38.

Ferede T, Ayenew AB, Hanjra MA, Hanjra M (2013) Agroecology matters: Impacts of climate change on agriculture and its implications for food security in Ethiopia. Global food security: Emerging issues and economic implications 71-112.

Filmer, D., \& Pritchett, L. H. (2001) Estimating wealth effects without expenditure data-or tears: an application to educational enrollments in states of India. Demography, 38 (1): 115132.

Fisher M, Chaudhury M, McCusker B (2010) Do forests help rural households adapt to climate variability? Evidence from Southern Malawi. World Development 38:1241-1250. 
Gbetibouo GA (2009) Understanding farmers' perceptions and adaptations to climate change and variability: the case of the Limpopo Basin, South Africa. In: International Food Policy Research Institute (IFPRI) Discussion paper 00849.

Gray C, Mueller V (2012) Drought and population mobility in rural Ethiopia. World Development 40(1): 134-145.

Grothmann T, Patt A (2005) Adaptive capacity and human cognition: the process of individual adaptation to climate change. Global Environmental Change 15:199-213.

Haggblade, S., Hazell, P. and Reardon, T. (2010). The rural non-farm economy: Prospects for growth and poverty reduction. World Development, 38.10: 1429-1441.

Hansen JW, Baethgen WE, Osgood DE, Ceccato PN, Ngugi RK (2007) Innovations in climate risk management: protecting and building rural livelihoods in a variable and changing climate. Journal of Semi-Arid Tropical Agricultural Research 4:1.

Hartter J, Stampone M D, Ryan SJ, Kirner K, Chapman CA, Goldman A (2012) Patterns and perceptions of climate change in a biodiversity conservation hotspot. PloS One 7: e32408.

HRD (Humanitarian Requirement Document) (2015) Ethiopia 2016: Joint Government and Humanitarian partners' Document. Addis Ababa: Federal Democratic Republic of Ethiopia. http://www.unicef.org/ethiopia/ECO_Ethiopia_HRD_2016.pdf. Accessed 1 June 2016

Hisali E, Birungi P, Buyinza F (2011) Adaptation to climate change in Uganda: evidence from micro level data. Global Environmental Change 21: 1245-1261.

IPCC (2014) Summary for policymakers. In: Climate Change 2014: Impacts, Adaptation, and Vulnerability. Part A: Global and Sectoral Aspects. Contribution of Working Group II to the Fifth Assessment Report of the Intergovernmental Panel on Climate Change [Field CB, Barros VR, Dokken DJ, Mach, KJ et al]. Cambridge University Press, Cambridge, United Kingdom New York, NY, USA, pp. 1-32.

Kassie B., Hengsdijk, H, Rötter R, Kahiluoto H, Asseng S, Van Ittersum M (2013). Adapting to climate variability and change: experiences from cereal-based farming in the Central Rift and Kobo Valleys, Ethiopia. Environmental Management 52: 1115-1131.

Klein RJT, Midgley GF, Preston BL et al (2014) Adaptation opportunities, constraints, and limits. In: Climate Change 2014: Impacts, Adaptation, and Vulnerability. Part A: Global and Sectoral Aspects. Contribution of Working Group II to the Fifth Assessment Report of the Intergovernmental Panel on Climate Change Cambridge University Press, Cambridge, United Kingdom and New York, NY, USA, pp.899-943.

Kuntashula E, Chabala L, Chibwe T, Kaluba P (2015) The Effects of Household Wealth on Adoption of Agricultural Related Climate Change Adaptation Strategies in Zambia. Sustainable Agriculture Research 4:88. 
Maddison DJ (2007) The perception of and adaptation to climate change in Africa. World Bank Policy Research Working Paper 4308.

Mertz O, Mbow C, Nielsen JØ, Maiga A, Diallo D et al. (2010) Climate factors play a limited role for past adaptation strategies in West Africa. Ecology and Society 15:25.

Moser C, Ekstrom JA (2010) A framework to diagnose barriers to climate change adaptation. Proceedings of the National Academy of Sciences 107:22026-22031.

Moser, C. (2011) A conceptual and operational framework for pro-poor asset adaptation to urban climate change. In Cities and Climate Change: Responding to an Urgent Agenda. (First ed.). Washington DC: World Bank Publications.

Müller C, Cramer W, Hare WL, Lotze-Campen, H (2011) Climate change risks for African agriculture. Proceedings of the National Academy of Sciences 108:4313-4315.

Mwangi WM (1996). Low use of fertilizers and low productivity in sub-Saharan Africa. Nutrient Cycling in Agroecosystems 47: 135-147.

Niang I, Ruppel OC, Abdrabo MA et al (2014) Africa In: Climate Change 2014: Impacts, Adaptation, and Vulnerability. Part B: Regional Aspects. Contribution of Working Group II to the Fifth Assessment Report of the Intergovernmental Panel on Climate Change. Cambridge University Press, Cambridge, United Kingdom and New York, NY, USA, pp. 1199-1265.

Nielsen JØ, Reenberg A (2010) Cultural barriers to climate change adaptation: A case study from Northern Burkina Faso. Global Environmental Change 20: 142-152.

NMSA (2001) National (Meteorological Services Agency). Initial National Communication of Ethiopia to the United Nations Framework Convention on Climate Change (UNFCCC).

NMSA, Addis Ababa, Ethiopia.

Paul SK, Routray JK. (2011) Household response to cyclone and induced surge in coastal Bangladesh: coping strategies and explanatory variables. Natural Hazards 57: 477-499.

Robinson S, Strzepek K, Cervigni R (2013) The Cost of Adapting to Climate Change in Ethiopia: Sector-Wise and Macro-Economic Estimates. Ethiopia Strategy Support Program II (ESSP) working Paper 53

Roco L, Engler A, Bravo-Ureta BE, Jara-Rojas R (2015) Farmers' perception of climate change in mediterranean Chile. Regional Environmental Change 15: 867-879.

Rowhani P, Lobell DB, Linderman M, Ramankutty N (2011) Climate variability and crop production in Tanzania. Agr Forest Meteorol 151:449-460.

Sabates-Wheeler, R., Mitchell, T., and Ellis, F (2008) Avoiding Repetition: Time for CBA to engage with the livelihoods literature. IDS Bulletin 39: 53-59. 
Seleshi Y, Zanke U (2004) Recent changes in rainfall and rainy days in Ethiopia. International Journal of Climatology 24: 973-983.

Silvestri S, Bryan E, Ringler C, Herrero M, Okoba B (2012) Climate change perception and adaptation of agro-pastoral communities in Kenya. Regional Environ Change 12:791-802.

Sivakumar MVK, Das HP, Brunini O (2005) Impacts of present and future climate variability and change on agriculture and forestry in the arid and semi-arid tropics. Climatic Change 70: $31-72$

Slegers MF (2008) "If only it would rain": Farmers' perceptions of rainfall and drought in semi-arid central Tanzania. J Arid Environ 72: 2106-2123.

Smit B, Burton I, Klein RJ, Wandel J (2000) An anatomy of adaptation to climate change and variability. Climatic Change 45:223-251.

Speranza CI, Kiteme B, Ambenje P, Wiesmann U, Makali S (2010) Indigenous knowledge related to climate variability and change: insights from droughts in semi-arid areas of former Makueni District, Kenya. Climatic Change 100:295-315.

Stein, A. and Moser, C. (2014) Asset planning for climate change adaptation: Lessons from Cartagena, Colombia. Environment and Urbanization, 26.1: 166-183.

Strzepek K, Mccluskey A (2006) District Level Hydro-climatic Time Series and Scenario Analysis to Assess the Impacts of Climate Change on Regional Water Resources and Agriculture in Africa. CEEPA Discussion Paper No. 13, Pretoria.

Tambo JA, Abdoulaye T (2012). Climate change and agricultural technology adoption: the case of drought tolerant maize in rural Nigeria. Mitigation and Adaptation Strategies for Global Change 17: 277-292.

Tambo JA, Abdoulaye T (2013) Smallholder farmers' perceptions of and adaptations to climate change in the Nigerian savanna. Regional Environ Change13: 375-388.

Tessema YA, Aweke CS, Endris GS (2013) Understanding the process of adaptation to climate change by small-holder farmers: the case of east Hararghe Zone, Ethiopia. Agricultural and Food Economics 1:13.

Thomas, DS, and Twyman, C (2003) Equity and Justice in Climate Change Adaptation amongst natural-resource dependent societies: Global Environmental Change 15: 115-124.

Thomas DS, Twyman C, Osbahr H, Hewitson B (2007) Adaptation to climate change and variability: farmer responses to intra-seasonal precipitation trends in South Africa. Climatic change 83:301-322.

Thornton PK, Herrero M, Freeman HA, Mwai AO, Rege E, Jones PG, McDermott J (2007) Vulnerability, climate change and livestock-opportunities and challenges for the poor. J Sat Agric Res 4:1-23. 
Thornton P, Robinson T, Kruska R, Jones P, McDermott J, Reid R (2005) Cattle Trypanosomiasis in Africa to 2030. UK Office of Science and Innovation. Foresight project Detection of Infectious Diseases: Preparing for the future. T8.8.

West CT, Roncoli C, Ouattara F (2008) Local perceptions and regional climate trends on the central plateau of Burkina Faso. Land Degrad Dev19: 289-304.

Wood SA, Jina AS, Jain M, Kristjanson P, DeFries RS (2014) Smallholder farmer cropping decisions related to climate variability across multiple regions. Global Environmental Change 25: 163-172.

Ziervogel G, Bharwani S, Downing TE (2006) Adapting to climate variability: pumpkins, people and policy. Natural Resources Forum 30: 294-305.

Zimmerman, F. J., \& Carter, M. R. (2003). Asset smoothing, consumption smoothing and the reproduction of inequality under risk and subsistence constraints. Journal of Development Economics, 71: 233-260. 